\title{
Arctigenin induces the apoptosis of primary effusion lymphoma cells under conditions of glucose deprivation
}

\author{
YUSUKE BABA, ZENPEI SHIGEMI, NAOKO HARA, MISATO MORIGUCHI, \\ MARINA IKEDA, TADASHI WATANABE and MASAHIRO FUJIMURO
}

Department of Cell Biology, Kyoto Pharmaceutical University, Yamashina-ku, Kyoto 607-8412, Japan

Received September 19, 2017; Accepted November 21, 2017

DOI: 10.3892/ijo.2017.4215

\begin{abstract}
Kaposi's sarcoma-associated herpesvirus (KSHV) is the causative agent of primary effusion lymphoma (PEL) and Kaposi's sarcoma. PEL is a type of non-Hodgkin's B-cell lymphoma, affecting immunosuppressed individuals, such as post-transplant or AIDS patients. However, since PEL is resistant to chemotherapeutic regimens, new effective treatment strategies are required. Arctigenin, a natural lignan compound found in the plant Arctium lappa, has been widely investigated as a potential anticancer agent in the clinical setting. In the present study, we examined the cytotoxic effects of arctigenin by cell viability assay and found that arctigenin markedly inhibited the proliferation of PEL cells compared with KSHV-uninfected B-lymphoma cells under conditions of glucose deprivation. Arctigenin decreased cellular ATP levels, disrupted mitochondrial membrane potential and triggered caspase-9-mediated apoptosis in the glucose-deprived PEL cells. In addition, western blot analysis using phosphospecific antibodies were used to evaluate activity changes in the signaling pathways of interest. As a result, arctigenin suppressed the activation of the extracellular signal-regulated kinase (ERK) and p38 mitogen-activated protein kinase
\end{abstract}

Correspondence to: Professor Masahiro Fujimuro, Department of Cell Biology, Kyoto Pharmaceutical University, MisasagiShichonocho 1, Yamashinaku, Kyoto 607-8412, Japan

E-mail: fuji2@mb.kyoto-phu.ac.jp

Abbreviations: ATF6 $\alpha$, activating transcription factor $6 \alpha$; ATP, adenosine triphosphate; EDEM, ER degradation enhancing $\alpha$-mannosidase-like protein; ER, endoplasmic reticulum; ERK, extracellular signal-regulated kinase; GRP78, glucose-regulated protein 78; BiP, immunoglobulin heavy-chain-binding protein; JNK, c-Jun N-terminal kinase; KSHV, Kaposi's sarcoma-associated herpesvirus; $\mathrm{NaB}$, sodium butyrate; 338 MAPK, p38 mitogen-activated protein kinase; PEL, primary effusion lymphoma; UPR, unfolded protein response

Key words: arctigenin, activating transcription factor 6, extracellular signal-regulated kinase, endoplasmic reticulum stress, glucose-regulated protein 78, Kaposi's sarcoma-associated herpesvirus, lignan, p38 mitogen-activated protein kinase, primary effusion lymphoma, unfolded protein response (p38 MAPK) signaling pathways by inhibiting ERK and p38 MAPK phosphorylation in the glucose-deprived PEL cells. We confirmed that an inhibitor of ERK (U0126) or p38 MAPK (SB202190 and SB203580) suppressed the proliferation of the BC3 PEL cells compared with the KSHV-negative DG75 cells. Moreover, RT-PCR and luciferase reporter assay revealed that arctigenin and p38 MAPK inhibition by SB202190 or SB203580 downregulated the transcriptional expression of unfolded protein response (UPR)-related molecules, including GRP78 and ATF6 $\alpha$ under conditions of glucose deprivation. Finally, we confirmed that arctigenin did not affect KSHV replication in PEL cells, suggesting that arctigenin treatment for PEL does not contribute to the risk of de novo KSHV production. These data thus indicate that arctigenin may serve as a lead compound for the development of novel and effective drugs for the treatment of PEL.

\section{Introduction}

Primary effusion lymphoma (PEL) is a rare subtype of large B-cell lymphoma and strongly linked with Kaposi's sarcomaassociated herpesvirus (KSHV) infection $(1,2)$. PEL is also termed body cavity-based lymphoma, and is classified as a type of non-Hodgkin's B-cell lymphoma affecting with immunocompromised patients, such as AIDS patients or those who have undergone organ transplantation $(1,2)$. PEL is usually present as a lymphomatous effusion in body cavities and is treated with CHOP therapy either alone or in combination with rituximab. However, PEL is resistant to these chemotherapy regimens (3), and is associated with a very poor prognosis (4-6). Currently, there is no effective treatment for PEL. KSHV, also known as human herpesvirus 8 (HHV8), is an oncogenic DNA virus and is classified in the $\gamma$-herpesvirus subfamily. As with other human herpesviruses, KSHV exists in either a latent or lytic infection state, which can persist long-term in the host after primary infection (7). During latency, the KSHV genome circularizes and forms a double-stranded episomal DNA molecule in infected cells such as PEL cells. KSHV expresses only a limited set of genes, including latency-associated nuclear antigen (LANA), v-FLIP, v-Cyclin and microRNAs, all of which strongly contribute to establishing latent infection $(7,8)$. These viral molecules constitutively and/or transiently activate signaling pathways, including nuclear factor- $\kappa \mathrm{B}(\mathrm{NF}-\kappa \mathrm{B})$, Akt, Wnt and extracellular signal-regulated kinase (ERK), 
which are essential for the malignant phenotype and cell survival of PEL (8-10). After re-activating the lytic infection state, most viral genes are expressed, and these viral gene products facilitate viral replication and the production of mature virions (11). We previously demonstrated that diallyl trisulfide, pyrrolidinium $\mathrm{C}_{60}$ fullerene, or sangivamycin induce the apoptosis of PEL cells via the inhibition of NF- $\mathrm{BB}$ (12), Akt (13), or ERK signaling (14), respectively. In addition, the unfolded protein response (UPR) pathway is downregulated in PEL cells; namely, IRE1 $\alpha$ and PERK are downregulated under normal culture conditions (15). Therefore, endoplasmic reticulum (ER)-stress inducers, including methylseleninic acid, sodium selenite and thapsigargin cause severe ER stress and subsequent apoptosis through pro-apoptotic UPR activation in PEL cells $(15,16)$.

Arctigenin, a representative dibenzylbutyrolactone lignin, is an extract from the burdock plant, Arctium lappa, whose seed has traditionally been used in Japanese Kampo medicine for detoxification and inflammation, including in mastitis. Arctigenin has been reported to exhibit many biological functions, such as anticancer, anti-inflammatory $(17)$, antiviral $(18,19)$, immunomodulatory, antioxidant (20), neuroprotective (20) and antidiabetic (21) activities, and has been shown to modulate cell signaling pathways, such as signal transducer and activator of transcription 3 (STAT3) (22), Akt $(23,24)$, NF-kB (24), p38 mitogen-activated protein kinase (p38 MAPK) $(25,26)$ and ERK $(24,27)$. In addition to affecting cell signaling, arctigenin influences ER stress and inhibits or activates the UPR, resulting in apoptosis or protection against ER stress (28-30). Arctigenin has been shown to exhibit anticancer activity in numerous types of cancer, including hepatocellular carcinoma (23), colon cancer (25), gastric cancer (31), pancreatic cancer (32), gallbladder cancer (27), breast cancer $(24,26)$, ovarian cancer (33) and pancreatic cancer $(34,35)$. One of the interesting anticancer properties of arctigenin is that it can preferentially induce the apoptosis of cancer cells under conditions of glucose starvation $(34,36)$. Furthermore, arctigenin (GBS-01) has presented a high safety profile and good therapeutic effects in a phase I clinical trial in patients with gemcitabine-refractory pancreatic cancer due to its anticancer and anti-austerity activity (35). However, the effects of arctigenin on aggressive PEL phenotypes remain unclear. In the present study, the effects of arctigenin on PEL cells and the underlying molecular mechanisms were investigated.

\section{Materials and methods}

Cell lines and reagents. KSHV-positive PEL cell lines (BC3, BCBL1, BC2 and HBL6) are derived from patients with PEL. PEL and KSHV-negative B-lymphoma cell lines (BJAB, Ramos and DG75) were kindly provided by Dr S.D. Hayward (Johns Hopkins University School of Medicine, Baltimore, MD, USA) and were cultured in RPMI-1640 medium supplemented with $10 \%$ fetal bovine serum. 2-Deoxyglucose, was dissolved in distilled sterile water, and arctigenin (both from Wako, Osaka, Japan), SB203580 (p38 MAPK inhibitor; Nacalai Tesque, Kyoto, Japan), SB202190 (p38 MAPK inhibitor; Nacalai Tesque) and U0126 (ERK inhibitor; Cell Signaling Technology, Beverly, MA, USA) were dissolved in dimethyl sulfoxide (DMSO).
Cell viability assay. The PEL cells and KSHV-negative cells were maintained in RPMI-1640 medium supplemented with $10 \%$ FCS. The cells were seeded in 96-well plates at $1 \times 10^{4}$ cells/well in $100 \mu \mathrm{l}$ of RPMI-1640 (or glucose-free RPMI-1640) with or without the compound at various concentrations and incubated for $24 \mathrm{~h}$. The number of viable cells was estimated using Cell Count Reagent SF (Nacalai Tesque), as previously described (12). The optical density at $450 \mathrm{~nm}$ of each sample was measured using a microplate spectrophotometer (Tecan M200; Tecan, Kanagawa, Japan) and expressed as a percentage of the value obtained from untreated cells (defined as 100\%).

Cell viability assay in the presence of 2-deoxyglucose. The cells $\left(1 \times 10^{4}\right.$ cells/well) were seeded onto 96-well plates in $100 \mu \mathrm{l}$ of RPMI-1640 medium. The cells were incubated in medium with $0,1,10,50,100$ or 1,000 $\mu \mathrm{M}$ 2-deoxyglucose for $24 \mathrm{~h}$ (Fig. 2A), or with $0,0.1,1,2.5,5,10$ or $20 \mu \mathrm{M}$ arctigenin in combination with $100 \mu \mathrm{M}$ 2-deoxyglucose for $24 \mathrm{~h}$ (Fig. 2B). The number of viable cells was evaluated using Cell Count Reagent SF (Nacalai Tesque).

Western blot analysis and antibodies. The cells $\left(1 \times 10^{6}\right.$ cells $)$ were lysed in $200 \mu$ l of sodium dodecyl sulfate-polyacrylamide gel electrophoresis (SDS-PAGE) sample buffer containing $0.5 \mathrm{mM}$ phenylmethylsulfonyl fluoride, $1 \mu \mathrm{g} / \mathrm{ml}$ pepstatin, $5 \mu \mathrm{g} / \mathrm{ml}$ aprotinin and 1\% 2-mercaptoethanol, boiled for $5 \mathrm{~min}$, and sonicated for $30 \mathrm{sec}$ with an immersible tip-type sonicater in order to shear the chromosomal DNA. The resulting lysate was subjected to SDS-PAGE on 8 or $12 \%$ polyacrylamide gel followed by western blot analysis. The proteins were transferred onto a ClearTrans nitrocellulose membrane (Wako) and, a membrane was incubated with $3 \%$ non-fat dry milk in phosphate-buffered saline (PBS) containing 0.1\% Tween-20 (PBS-T) for $1 \mathrm{~h}$ at room temperature. The membrane was then incubated with the primary antibody (1,000-fold dilution) and subsequently with the secondary antibody (horseradish peroxidase-conjugated anti-mouse or anti-rabbit IgG antibody) (3,000-fold dilution) in Can Get Signal Immunoreaction Enhancer Solution (Toyobo, Osaka, Japan). The antibody-reactive bands were visualized by ECL Western Blotting Detection Reagents (GE Healthcare Life Sciences, Chicago, IL, USA), and the bands were visualized with X-ray film (Fujifilm Corp., Tokyo, Japan). The primary antibodies used in these experiments were as follows: $\beta$-actin (sc-69879), ribosomal protein S6 kinase A1/RSK-1 (sc-393147) and activating transcription factor (ATF) $6 \alpha$ (H-280) (sc-22799) (all from Santa Cruz Biotechnology, Inc., Santa Cruz, CA, USA), cleaved caspase-3 (\#9661), cleaved caspase-9 (\#9501), cleaved PARP (\#9541), Thr202/Tyr204-phospho-ERK1/2 (\#9101), Ser380phospho-p90RSK (\#11989) (all from Cell Signaling Technology, Danvers, MA, USA), Thr180/Tyr182-phospho-p38 MAPK (612288), p38 MAPK (612168), Thr183/Tyr185-phospho-SAPK/ JNK (612540), SAPK/JNK (610627), Thr202/Tyr204phospho-ERK1/2 (20A) (612359), ERK1/2 (610103) and pan ERK (610123) (all from BD Biosciences, Franklin Lakes, NJ, USA).

JC-1 staining for assessment of mitochondrial membrane potential. The inner mitochondrial membrane potential was evaluated by cell staining with JC-1 (PromoCell GmbH, 
Table I. Primers for used for RT-PCR.

\begin{tabular}{lll}
\hline Molecule & \multicolumn{1}{c}{ Forward } & Reverse \\
\hline EDEM2 & 5'-TGCCTTTCCCTTCGATGAGC-3' & 5'-ACATCTTCGAACACCGGGTC-3' \\
EDEM1 & 5'-TGGACTGCAGGTGCTGATAG-3' & 5'-GACTTTCCCCCTTGGTCCTG-3' \\
GADD34 & 5'-CGAGGAAGAGGGAAGTTGCTG-3' & 5'-CTCCATCCTTCTCAGCTGCC-3' \\
GRP94 & 5'-GCCAGTTTGGTGTCGGTTTC-3' & 5'-GTGATGAATACACGGCGCAC-3' \\
CHOP & 5'-GGTACCTATGTTTCACCTCCTG-3' & 5'-GAGCCGTTCATTCTCTTCAGC-3' \\
GRP78 & 5'-AGGAAAGACAATAGAGCTGTGC-3' & 5'-TGTCTTTTGTCAGGGGTCTTTC-3' \\
ATF6 $\alpha$ & 5'-CTTTACTAGGCCACCCCGTCTCG-3' & 5'-CAATCCAACTCCTCAGGAAC-3' \\
GAPDH & 5'-TGACCACAGTCCATGCCATC-3' & 5'-GGGGAGATTCAGTGTGGTGG-3'
\end{tabular}

RT-PCR, reverse transcription-polymerase chain reaction; EDEM, endoplasmic reticulum degradation enhancing $\alpha$-mannosidase-like protein; GRP, glucose-regulated protein; ATF, activating transcrition factor; GAPDH, glyceraldehyde 3-phosphate dehydrogenase.

Heidelberg, Germany), a cationic fluorescent dye that exhibits a fluorescence emission shift upon aggregation from $530 \mathrm{~nm}$ (green 'JC-1 monomer') to $590 \mathrm{~nm}$ (red 'JC-1 aggregates'). In healthy cells with a high mitochondrial membrane potential, JC-1 enters the mitochondrial matrix in a potential-dependent manner and forms JC-1-aggregates, resulting in a red fluorescence signal, whereas mitochondrial damage induces mitochondrial depolarization and monomeric JC-1, resulting in a green fluorescence signal. The cells in a 96-well plate were cultured with $2 \mathrm{mg} / \mathrm{ml} \mathrm{JC}-1$ for $30 \mathrm{~min}$ and washed with PBS. The cells were then incubated with or without arctigenin for $30 \mathrm{~min}$, and red fluorescence $(535 \mathrm{~nm}$ excitation and $590 \mathrm{~nm}$ emission) and green fluorescence (485 nm excitation and $530 \mathrm{~nm}$ emission) were measured using a 96-well plate fluorometer (Tecan M200). The polarization of mitochondrial membrane potential, i.e., normality, are shown as the ratio of $\mathrm{red} / \mathrm{green}$ fluorescence.

Determination of cellular ATP concentration. The cells were seeded in 96-well plates at $5 \times 10^{4}$ cells/well in $0.1 \mathrm{ml}$ of medium and incubated with or without arctigenin for $3 \mathrm{~h}$. The cellular ATP concentration was measured using the ATP assay reagent (Wako) according to the manufacturer's instructions. Luminescence was measured using a luminescence microplate leader (Tecan M200). The ATP concentration of the untreated cells was defined as $100 \%$.

Cell viability assay using the kinase inhibitor. The cells $\left(1 \times 10^{4}\right.$ cells/well) were cultured in $100 \mu 1$ of glucose-free RPMI-1640 with or without the kinase inhibitors (U0126, SB202190 or SB203580) at various concentrations for $24 \mathrm{~h}$. The number of viable cells was estimated using Cell Count reagent $\mathrm{SF}$ (Nacalai Tesque).

Reverse transcription-polymerase chain reaction (RT-PCR). Total RNA was purified and extracted from $1 \times 10^{6}$ cells using RNAiso Plus (Takara Bio Inc., Shiga, Japan), as previously described (12). First Strand cDNA was synthesized from $20 \mathrm{ng}$ of total RNA using the ReverTra Ace qPCR RT kit (Toyobo). To quantify cDNA, polymerase chain reaction (PCR) was performed using GoTaq Flexi DNA Polymerase (Promega, Madison, WI, USA). The PCR products were analyzed by electrophoresis on $2 \%$ agarose gels and staining with ethidium bromide. The nucleotide sequences of oligonucleotides used for RT-PCR primers are shown in Table I.

Luciferase reporter assay. HeLa cells were obtained from RIKEN BioResource Center (Ibaragi, Japan) and used for transient transfection. HeLa cells $\left(1 \times 10^{5}\right)$ were transfected with $2 \mu \mathrm{g}$ of a luciferase reporter plasmid containing either the promoter of the glucose-regulated protein 78 (GRP78)/BiP gene (pGL3-BiP) or the promoter of the ATF6 gene plasmid (pGL3-ATF6), together with $1 \mu \mathrm{g}$ of a pSV- $\beta$-Gal plasmid (Promega) by the Chen and Okayama calcium-phosphate method (37). pGL3-BiP and pGL3-ATF6 which bear the promoter region of the GRP78/BiP gene and ATF6 $\alpha$ gene upstream of the luciferase gene, respectively, were kind gifts from Takayanagi et al (38). pSV- $\beta$-Gal was used as an internal control for the determination of the transfection efficiency. The transfected cells were incubated in glucose-free medium with arctigenin (or kinase inhibitor) for $4 \mathrm{~h}$. The cells were resuspended in $0.1 \mathrm{ml}$ of lysis buffer for luciferase and $\beta$-Gal assay. Luciferase activity was measured using GloMax 20/20 luminometer (Promega). The luciferase activity divided by $\beta$-galactosidase activity in untreated cells cultured in glucosefree medium was defined as $100 \%$.

Real-time PCR for the measurement of viral production. The measurement of lytic virus production was performed as previously described (12). Briefly, the BC3 cells were treated with $3 \mathrm{mM}$ sodium butyrate $(\mathrm{NaB})$ together with arctigenin for $48 \mathrm{~h}$, and the culture media $(300 \mu \mathrm{l})$ were harvested. To obtain only enveloped and encapsulated viral genomes, media were incubated with 20 units of DNase I (Wako) for $30 \mathrm{~min}$, and viral DNA was purified using a QIAamp DNA blood mini kit (Qiagen, Hilden, Germany). Viral DNA was quantified by real-time PCR using an ORF50 (RTA)-specific primer set (forward, 5'-ATA ATC CGA ATG CAC ACA TCT TCC ACC AC-3' and reverse, 5'-TTC GTC GGC CTC TCG GAC GAA CTG A-3').

Statistical analysis. All data are presented as the means \pm standard deviation (SD) from at least 3 independent experiments. Statistical significance was determined by one-way ANOVA 

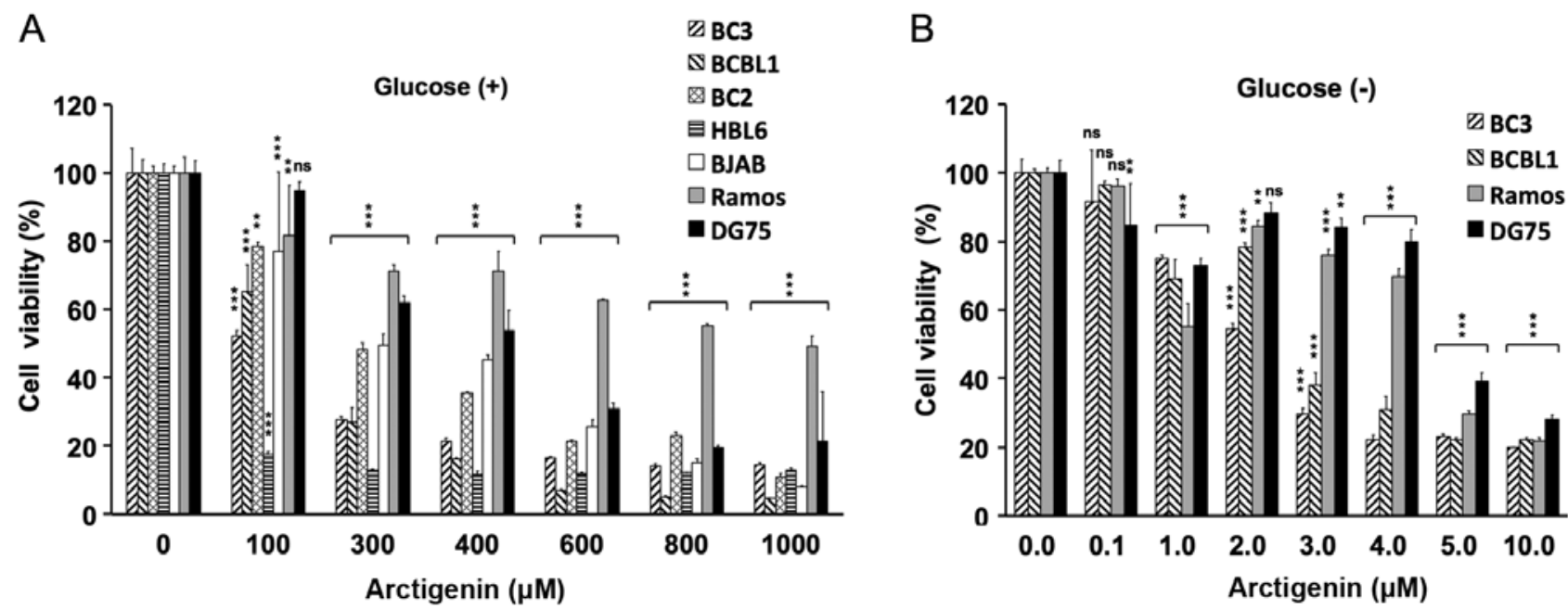

Figure 1. Cytotoxic effects of arctigenin on PEL cells cultured in normal or glucose-free media. (A and B) Cytotoxic effects of arctigenin on B-lymphoma cells cultured in glucose-containing medium [glucose (+)] or glucose-deprived medium [glucose (-)], respectively. KSHV-positive PEL cells (BC3, BCBL1, BC2 and HBL6) and KSHV-negative B-lymphoma cells (BJAB, Ramos and DG75) were incubated in RPMI-1640 (or glucose-free RPMI-1640) medium with various concentrations of arctigenin for $24 \mathrm{~h}$ and subjected to cell viability assays. The optical density at $450 \mathrm{~nm}$ was measured, and the values of the respective untreated cells are defined as $100 \%$. ${ }^{* *} \mathrm{P}<0.001$ and ${ }^{* * *} \mathrm{P}<0.0001$ indicate a statistically significantly difference compared with the untreated cells (one-way ANOVA followed by Tukey's test, respectively). ns, not significant.

Table II. The $\mathrm{CC}_{50}$ value of arctigenin in B-lymphoma cells under the glucose-supplied or -deprived conditions.

\begin{tabular}{lcccccrr}
\hline & \multicolumn{7}{c}{ Cell line } \\
\cline { 2 - 7 } & BC3 & BCBL1 & BC2 & HBL6 & BJAB & Ramos & DG75 \\
\hline Glucose $(+)$ & 273.2 & 193.8 & 107.0 & 0.4 & 101.8 & 819.0 & 561.8 \\
CC $_{50}(\mu \mathrm{M})$ & 2.8 & 2.3 & n.d. & n.d. & n.d. & 4.5 & 4.2 \\
$\begin{array}{l}\text { Glucose }(-) \\
\mathrm{CC}_{50}(\mu \mathrm{M})\end{array}$ & & & & & & & \\
\hline
\end{tabular}

$\mathrm{CC}_{50}$, cytotoxic concentration that reduces cell viability by $50 \%$. n.d., not determined.

followed by Tukey's test for multiple comparisons using GraphPad PRISM 7 (GraphPad Software, La Jolla, CA, USA).

\section{Results}

Arctigenin exhibits preferential cytotoxicity against PEL cells under conditions of glucose deprivation. First, the proliferation of PEL cells and KSHV-uninfected B-cell lymphoma cells was measured in normal medium containing arctigenin, and the cytotoxicity was evaluated by analyzing the viability of the treated vs. the untreated cells (Fig. 1A). Arctigenin preferentially inhibited the proliferation of the PEL cell lines (BC3, BC2, BCBL1 and HBL6) compared with the KSHV-uninfected B-lymphoma cell lines (BJAB, DG75 and Ramos). We then evaluated the cytotoxic effects of arctigenin on PEL cells cultured in glucose-free medium. As a result, at low concentrations (2-4 $\mu \mathrm{M})$, arctigenin exerted preferential growth inhibitory effects on PEL cells (Fig. 1B). In particular, the viability of the BC 3 and BCBL1 cells was decreased by $70 \%$ following treatment with $3 \mu \mathrm{M}$ arctigenin in glucose-deprived medium (Fig. 1B). By contrast, a 100-fold greater concentration of arctigenin $(300 \mu \mathrm{M})$ was needed to decrease the viability of these cells by $70 \%$ in glucosecontaining media (Fig. 1A). The cytotoxic effects $\left(\mathrm{CC}_{50}\right)$ of arctigenin on B-lymphoma cells under the glucose-supplied and glucose-deprived conditions are summarized in Table II. Arctigenin was active against not only the PEL (BC3, BCBL1, $\mathrm{BC} 2$ and HBL6), but also the KSHV-uninfected BJAB cells (Fig. 1A). These phenomena may be due to differences in the genetic background or differentiation status of the tested cells. Arctigenin exhibited potent anti-proliferative activities in the BC3 and BCBL1 cells in a dose- and glucose starvationdependent manner, but did not have the same effects on the DG75 and Ramos cells. Therefore, we focused and analyzed the underlying molecular machinery in the $\mathrm{BC} 3, \mathrm{BCBL} 1$, Ramos and DG75 cells.

Combination of arctigenin and 2-deoxyglucose synergistically suppresses the proliferation of PEL cells. Arctigenin exhibited preferential cytotoxicity against the PEL cells under conditions of glucose deprivation. Therefore, we investigated whether treatment with a low concentration of arctigenin in combination with 2-deoxyglucose, a hexokinase inhibitor of glycolysis, inhibits the proliferation of PEL cells under 
A

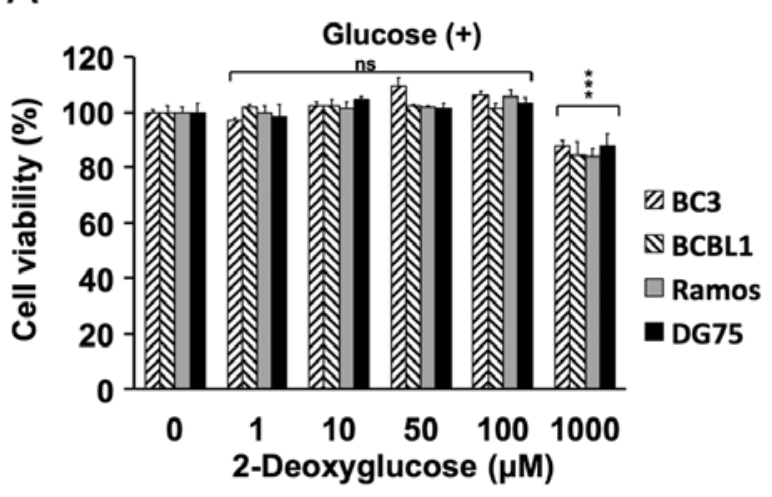

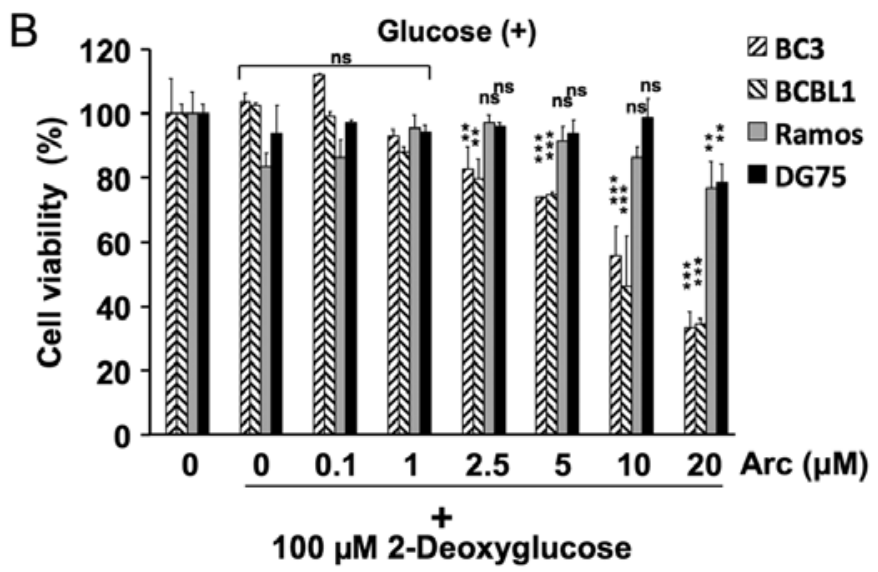

Figure 2. Arctigenin inhibits the proliferation of PEL cells under conditions of glucose deprivation more potently than under normal conditions. (A) Cytotoxic effects of 2-deoxyglucose on B-lymphoma cells cultured in normal medium. PEL cells (BC3 and BCBL1) and uninfected lymphoma cells (Ramos and DG75) were incubated in normal medium (glucose ${ }^{+}$) with $0,1,10,50,100$ or $1,000 \mu \mathrm{M}$ of 2-deoxyglucose for $24 \mathrm{~h}$ and subjected to cell viability assays. The values of the respective untreated cells are defined as 100\%. (B) Cytotoxic effects of a combined arctigenin and 2-deoxyglucose treatment on PEL cells cultured in normal medium. The cells were incubated in normal medium with various concentrations of arctigenin (Arc) in combination with $100 \mu \mathrm{M}$ of 2 -deoxyglucose for $24 \mathrm{~h}$. The values of the respective untreated cells are defined as $100 \%{ }^{*}{ }^{* *} \mathrm{P}<0.001$ and ${ }^{* * *} \mathrm{P}<0.0001$ indicate a statistically significantly difference compared with the untreated cells. ns, not significant.

normal glucose conditions. First, we examined the cytotoxic effects of 2-deoxyglucose on the PEL (BC3 and BCBL1) and KSHV-uninfected (Ramos and DG75) cell lines cultured in glucose-containing medium. Treatment with 2-deoxyglucose alone did not inhibit the growth of these cell lines (Fig. 2A). We then combined arctigenin at various concentrations $(0-20 \mu \mathrm{M})$ with $100 \mu \mathrm{M}$ of 2-deoxyglucose to examine the effects on PEL cells cultured in glucose-containing medium. As shown in Fig. 2B, the combination of arctigenin and 2-deoxyglucose synergistically decreased the viability of the PEL cells under normal glucose conditions, but did not decrease the viability of the KSHV-uninfected cells. Hence, arctigenin inhibited the proliferation of PEL cells under glucose-deprived conditions more potently than under normal glucose conditions.

Arctigenin induces the caspase-9-mediated apoptosis of glucose-starved PEL cells. We then examined whether the anti-proliferative effects of arctigenin under conditions of glucose deprivation are due to apoptotic cell death. The PEL cells cultured in glucose-free medium were treated with/or without $5 \mu \mathrm{M}$ arctigenin and were then examined by western blot analysis using cleaved caspase and PARP antibodies (Fig. 3A). Active caspase- 9 and -3 were detected in the arctigenin-treated BC3 PEL cells. In a time-dependent manner, the cleaved caspase-9, -3 and PARP fragments were increased in the glucose-starved BC3 cells treated with arctigenin, whereas modest cleaved caspase- 9 and PARP were detected in the arctigenin-untreated BC3 cells. However, no significant cleavage of caspases and PARP was detected in the untreated $\mathrm{BC} 3$ cells cultured in glucose-containing medium. In addition, cleaved caspase- 8 was not detected in the arctigenin-treated BC3 cells (data not shown).

Arctigenin induces mitochondrial disruption in glucosestarved PEL cells by decreasing ATP levels and disrupting the mitochondrial membrane. To gain insight into the molecular mechanisms through which arctigenin induces apoptosis via caspase- 9 activation, we examined whether arctigenin induces mitochondrial disruption in glucose-starved BC3 PEL cells. The BC3 and KSHV-uninfected Ramos cells cultured in glucose-free medium were treated with arctigenin for $30 \mathrm{~min}$, and the inner mitochondrial membrane potential of the cells was evaluated by JC-1 staining. As a result, arctigenin preferentially depolarized the mitochondrial membrane in the BC3 cells compared with the Ramos cells, which was indicated by a decrease in the red/green ratio (Fig. 3B). To obtain further evidence of mitochondrial dysfunction induced by arctigenin, the effects of arctigenin on the cellular ATP concentration in glucose-starved BC3 and Ramos cell lines were examined (Fig. 3C and D). Treatment with 2-deoxyglucose (also termed 2-DG) was used for the glucose-starvation of the cells. The results revealed that cellular ATP production decreased to $\sim 30 \%$ in both cell lines treated with arctigenin and 2-deoxyglucose (Fig. 3C), and arctigenin preferentially suppressed ATP production in BC3 cells cultured in glucose-free medium, compared with the Ramos cells (Fig. 3D). Thus, our data demonstrated that arctigenin impaired normal mitochondrial function and homeostasis in glucose-deprived PEL cells, resulting in the depolarization of mitochondrial membrane potential and a decrease in ATP production. Furthermore, mitochondrial disruption can induce caspase-9-mediated apoptosis. As regards cell viability (Fig. 2B) and ATP production (Fig. 3C) under glucose-supplied conditions, co-treatment with arctigenin and 2-deoxyglucose decreased the viability of the Ramos and BC3 cells. However, the co-treatment led to a decrease in ATP production in both the Ramos and BC3 cells to a varying extent, which may be due to differences in the ability of the cells to respond to ATP depletion or a difference in the inhibitory effect of 2-deoxyglucose on ATP production between the Ramos and BC3 cells.

Arctigenin suppresses ERK and p38 MAPK signaling in PEL cells under conditions of glucose-deprivation. Arctigenin is known to exert anticancer effects by modulating cellular signaling, including p38 MAPK $(25,26)$ and ERK $(24,27)$. On the other hand, the activation of the p38 MAPK $(39,40)$ and 


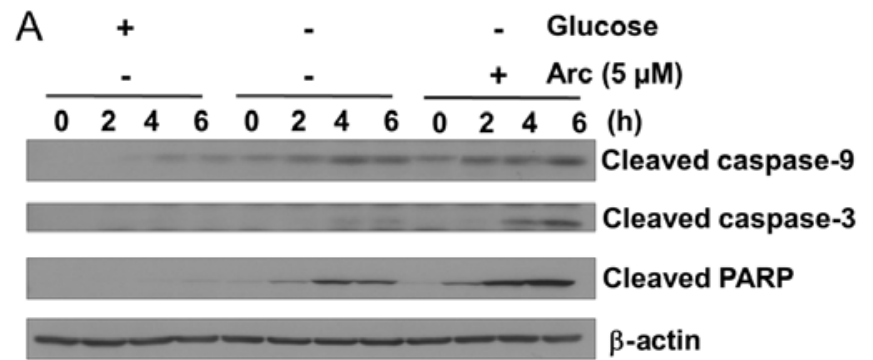

B

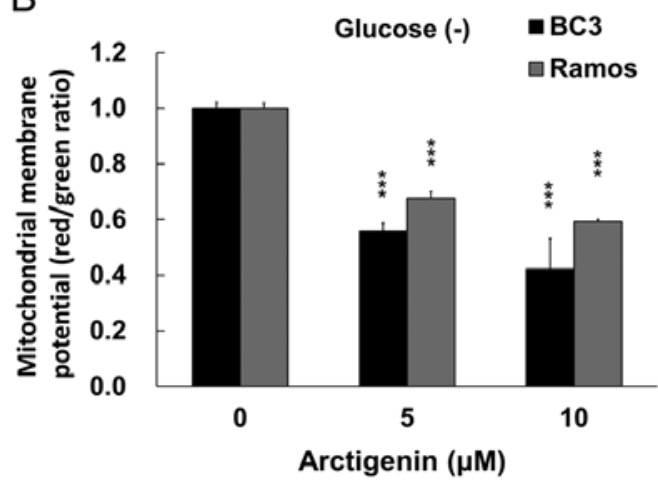

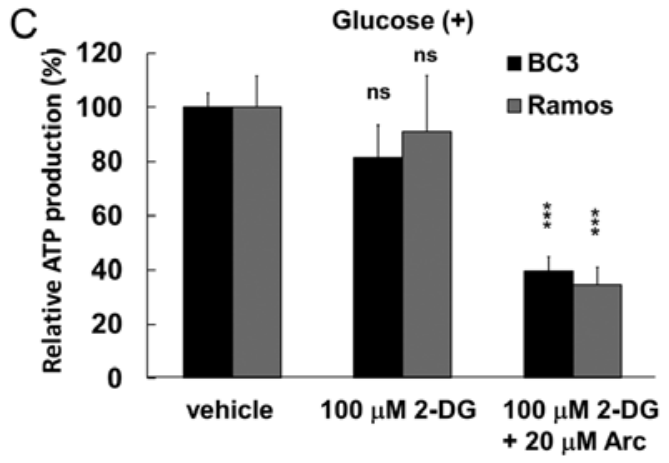

D

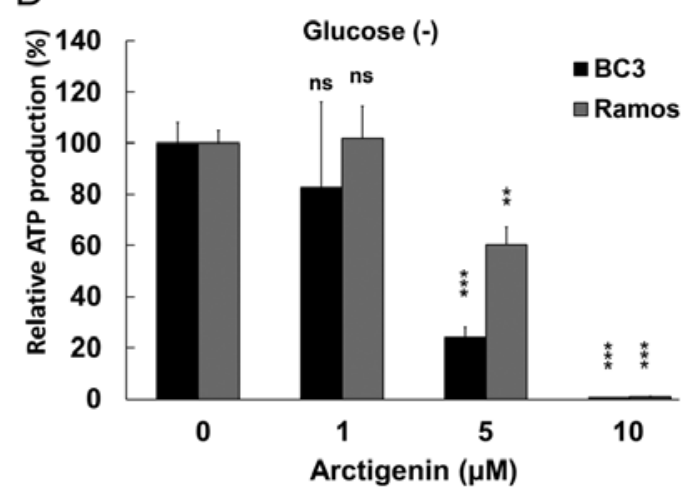

Figure 3. Arctigenin induces mitochondrial disruption and the caspase-9 mediated apoptosis of glucose-deprived PEL cells. (A) Western blot analysis using antibodies against caspase-9 and -3 , and cleaved PARP. BC3 PEL cells were cultured in glucose-free medium with (or without) $5 \mu \mathrm{M}$ arctigenin for $0-12$ h. (B) Arctigenin induced mitochondrial membrane disruption in PEL cells cultured in glucose-free medium. The glucose-deprived BC3 PEL cells or uninfected Ramos cells were treated with arctigenin (Arc) for $30 \mathrm{~min}$, and harvested cell samples were subjected to JC-1 staining to measure the inner mitochondrial membrane potential. A decrease in the red/green ratio indicates mitochondrial damage (depolarization of mitochondrial membrane potential). The values obtained from arctigenin-untreated cells were set at 1.0 . ${ }^{* * *} \mathrm{P}<0.0001$ indicates a statistically significantly difference compared with the untreated cells (C) Suppression of cellular ATP production in PEL cells by 2-deoxyglucose and arctigenin. PEL cells (BC3) or uninfected cells (Ramos) cultured in normal medium were incubated with $100 \mu \mathrm{M}$ 2-deoxyglucose (2-DG) in the presence (or absence) of $20 \mu \mathrm{M}$ arctigenin (Arc) for $3 \mathrm{~h}$. 2-Deoxyglucose was used for the glucose-starvation of the cells. The cellular ATP concentration of the untreated cells is defined as $100 \%$. Vehicle group indicates treatment with dimethyl sulfoxide (DMSO). ${ }^{* * *} \mathrm{P}<0.0001$ indicates a statistically significantly difference compared with the untreated cells. (D) Decrease in ATP production in glucosedeprived PEL cells induced by arctigenin. BC3 and Ramos cells cultured in glucose-free medium were incubated with $0,1,5$ and $10 \mu \mathrm{M}$ of arctigenin for $3 \mathrm{~h}$ The cellular ATP concentration of the untreated cells is defined as $100 \%$. $^{* *} \mathrm{P}<0.001$ and ${ }^{* * *} \mathrm{P}<0.0001$ indicate a statistically significantly difference compared with the untreated cells; ns, not significant.

ERK $(14,41,42)$ signaling pathways is necessary for KSHV to establish infection, maintain malignant phenotypes and ensure survival in host cells. Therefore, in this study, we investigated the effects of arctigenin treatment on MAPK signaling, including p38 MAPK, ERK and JNK, in cells cultured in glucosedeprived medium. The phosphorylation (i.e., activation) level of JNK was not markedly altered in the glucose-deprived cells by arctigenin (Fig. 4A), while the phosphorylation of p38 MAPK and ERK1/2 was decreased in the PEL cells (BC3 and BCBL1) treated with arctigenin for 4 and $6 \mathrm{~h}$. In addition, we examined the phosphorylation of p90RSK, which is an ERK substrate. The phosphorylation of ERK1/2 was also confirmed by a different antibody. U0126 treatment was used as a control for the inhibition of MEK1/2/ERK1/2 signaling. Compared to the KSHV-uninfected Ramos and DG75 cells, arctigenin markedly decreased the phosphorylation of p90RSK and ERK1/2 in the glucose-deprived PEL cells in a dose-dependent manner (Fig. 4B). These results indicate that the apoptotic effects of arctigenin are related to the modulation of the ERK and p38 MAPK signaling pathways.

The inhibition of either ERK or p38 MAPK signaling suppresseses the proliferation of glucose-deprived PEL cells.
Arctigenin led to a decrease in PEL cell proliferation through apoptosis (Figs. 1 and 3), and moreover suppressed ERK and p38 MAPK signaling (Fig. 4) in PEL cells under conditions of glucose deprivation. We therefore wished to examine the cytotoxic effects of a MEK inhibitor and p38 MAPK inhibitors on PEL cells to confirm that ERK and JNK signaling contribute to the survival and growth of PEL cells under conditions of glucose deprivation. U0126 is known to inhibit MEK1 and MEK2, which phosphorylate and activate ERK1/2. SB202190 and SB203580 inhibit p38 MAPK activity by competing with ATP for binding in the ATP-binding pocket of $\mathrm{p} 38$, respectively. When the BC3 PEL and KSHV-uninfected DG75 cells were treated with $50 \mu \mathrm{M}$ U0126, $50 \mu \mathrm{M}$ SB202190 or $100 \mu \mathrm{M}$ SB203580 for $24 \mathrm{~h}$, the viability of the glucose-deprived BC3 cells was decreased compared to that of the DG75 cells (Fig. 5). These data indicate that ERK and p38 MAPK signaling strongly contribute to the survival and proliferation of PEL cells. In addition, we evaluated the anti-proliferative effects of the inhibitors under glucose-supplied conditions. SB202190 and SB203580 did not exert any anti-proliferative effects on the PEL cells cultured in glucose-containing medium (data not shown). We have also previously reported the anti-proliferative effects of U1026 $(13,14)$. The viability of the BC3 cells cultured 


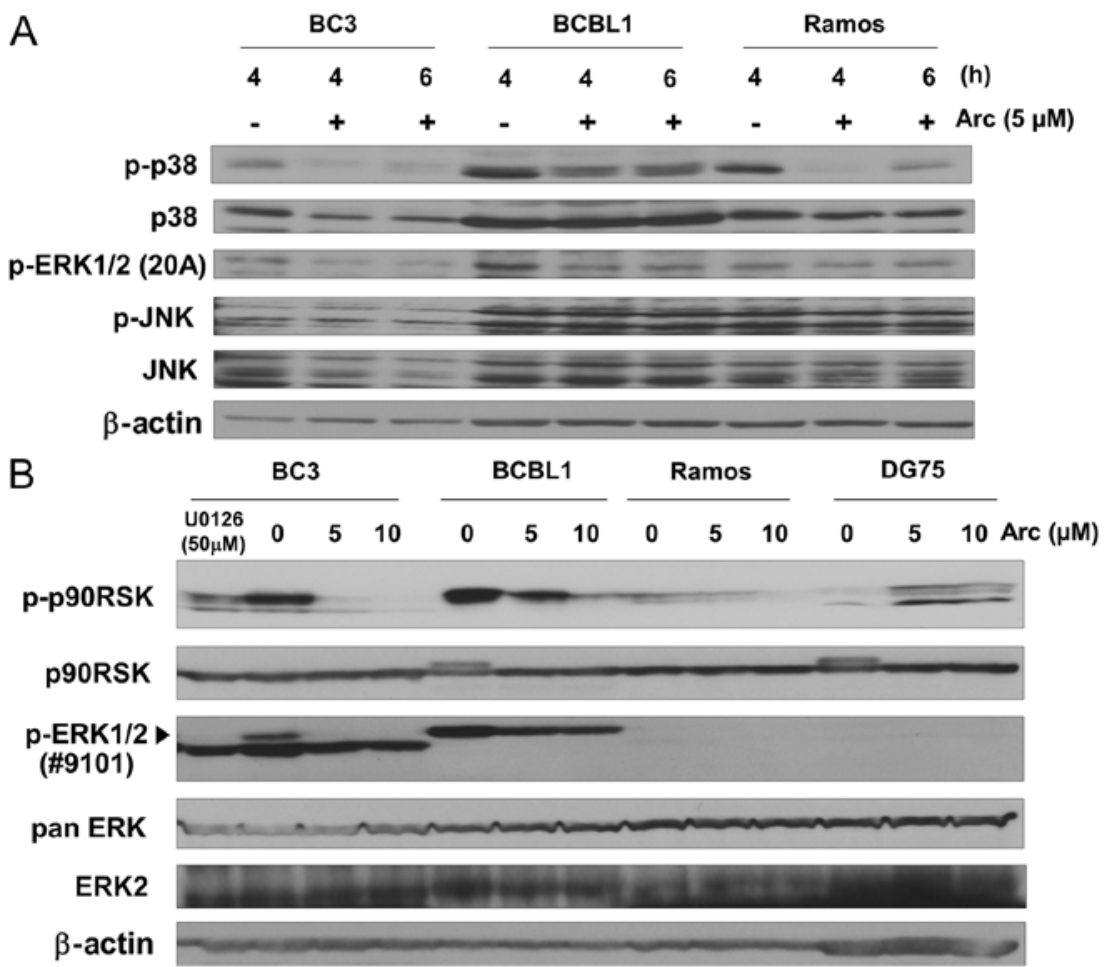

Figure 4. Arctigenin suppresses ERK and p38 MAPK signaling in glucose-deprived PEL cells. (A) Western blot analysis of the phosphorylation of p38, ERK1/2, and JNK in arctigenin-treated B-lymphoma cells. PEL cells (BC3 and BCBL1) and infected Ramos cells were cultured in glucose-free medium with $5 \mu \mathrm{M}$ arctigenin (Arc) for 4 or $6 \mathrm{~h}$, or cultured without arctigenin for $4 \mathrm{~h}$. Whole-cell lysates were subjected to western blot analysis with an anti Thr202/Tyr204-phospho-ERK1/2 (20A), Thr180/Tyr182-phospho-p38, p38, Thr183/Tyr185-phospho-JNK or JNK antibodies. (B) Western blot analysis of phosphorylated p90RSK in arctigenin-treated PEL cells. PEL and uninfected cells (Ramos and DG75) were cultured in glucose-free medium with 0, 5 or $10 \mu \mathrm{M}$ arctigenin for $3 \mathrm{~h}$, or BC3 cells were cultured in glucose-free medium with $50 \mu \mathrm{M}$ U0126 for $3 \mathrm{~h}$. U0126 was used as an inhibitor of MEK1/2-ERK1/2 signaling. Cell extracts were subjected to blotting with anti Ser380-phospho-p90RSK, p90RSK, Thr202/Tyr204-phospho-ERK1/2 (\#9101), pan ERK, or ERK2 antibodies. The pan ERK antibody recognizes ERK1, 2 and 3. The arrowhead indicates phosphorylated ERK1/2.

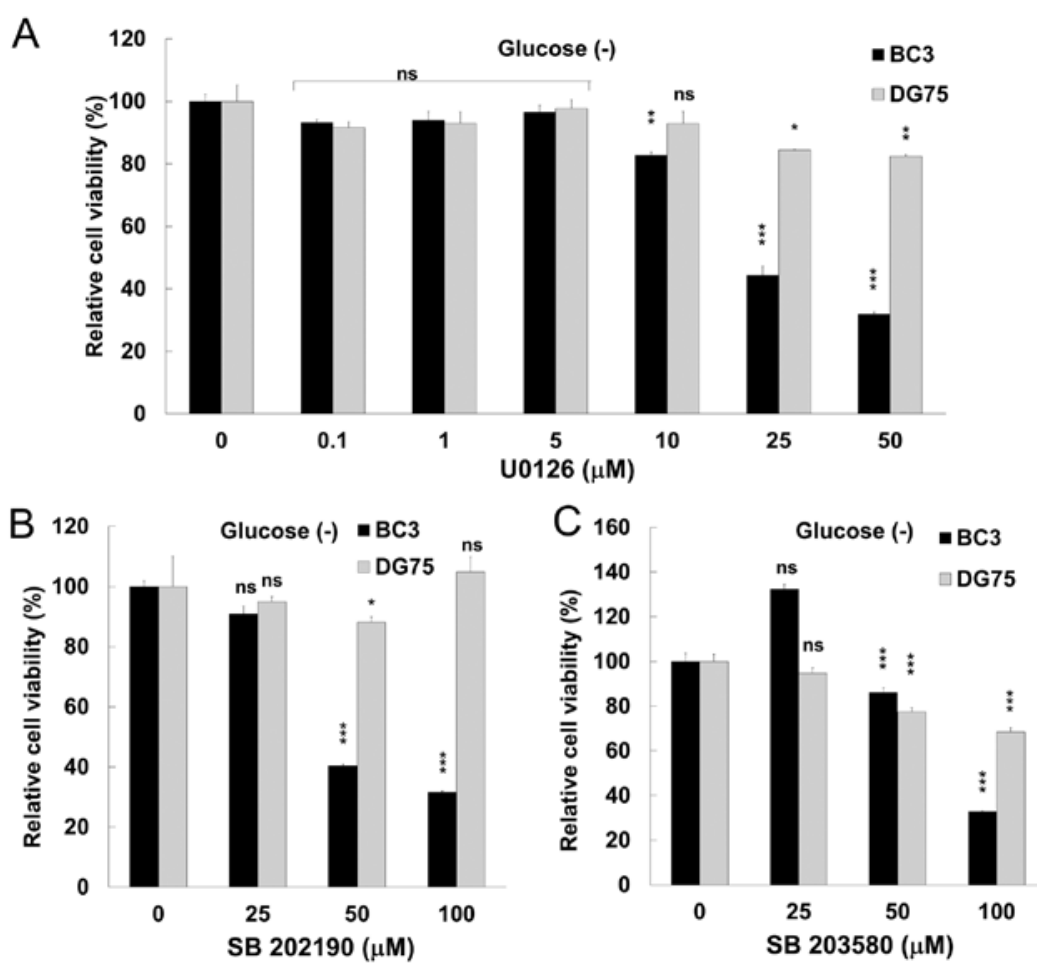

Figure 5. Inhibition of either ERK or p38 MAPK signaling suppresses the proliferation of PEL cells under conditions of glucose deprivation. (A-C) Cytotoxic effects of U0126 (MEK1/2 inhibitor), SB 202190 (p38 MAPK inhibitor) and SB203580 (p38 MAPK inhibitor), respectively, on BC3 PEL and uninfected DG75 cells. U0126 is an inhibitor of MEK1/2, which phosphorylates and activates ERK1/2. BC3 and DG75 cells were incubated with various concentrations of U0126, SB202190 and SB203580 for $24 \mathrm{~h}$ and subjected to viability assays. The values of the respective untreated cells are set at $100 \%$. "P<0.01, ${ }^{* *} \mathrm{P}<0.001$ and ${ }^{* * * *} \mathrm{P}<0.0001$ indicate a statistically significantly difference compared with the untreated cells; ns, not significant. 

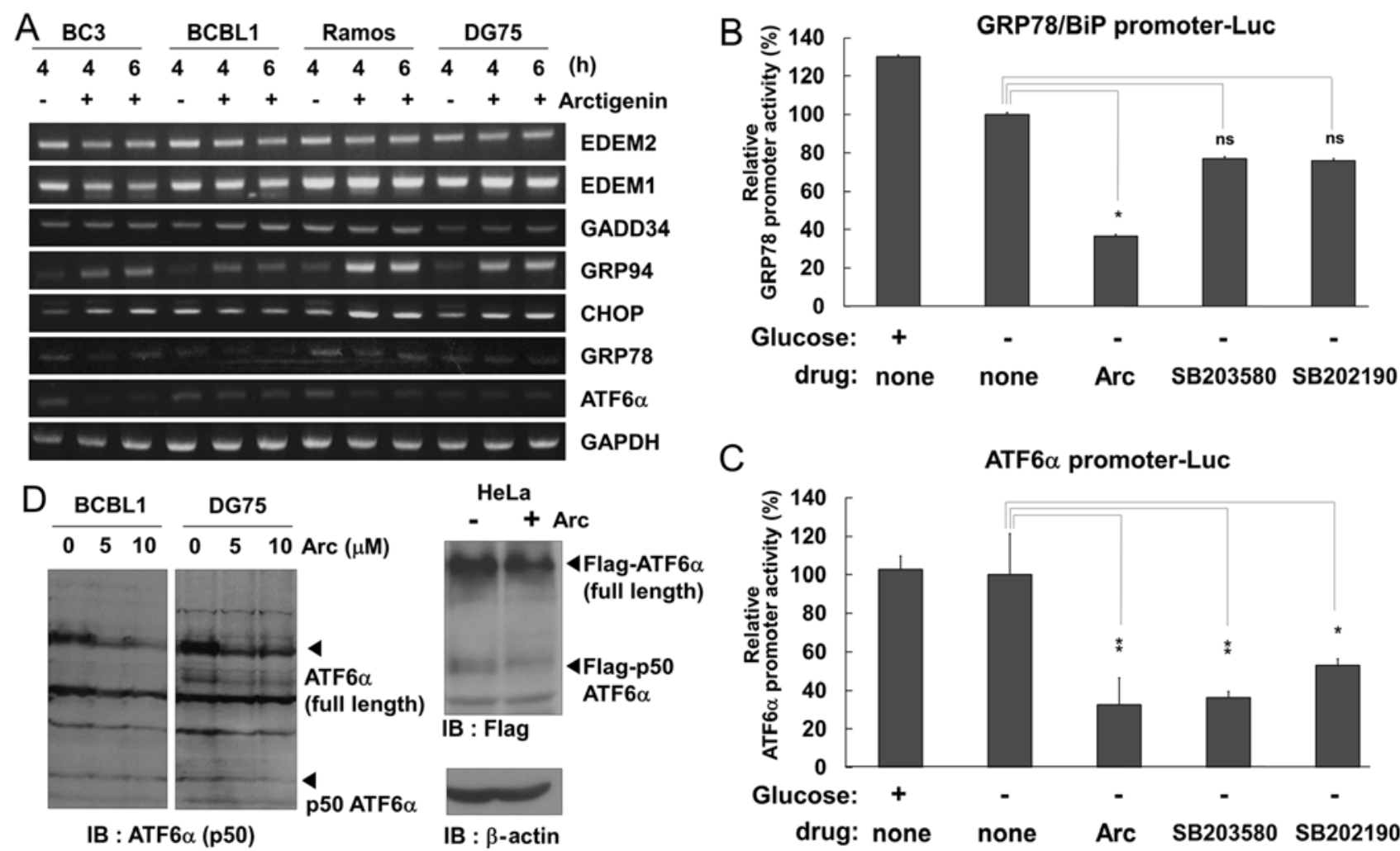

Figure 6. Arctigenin and p38 MAPK inhibitor suppress the transcriptional expression of GRP78 and ATF6 $\alpha$ in glucose-deprived PEL cells. (A) Effects of arctigenin on the mRNA expression of the UPR- and ER-stress related molecules. PEL cells (BC3 and BCBL1) and uninfected cells (Ramos and DG75) cells were treated with or without $5 \mu \mathrm{M}$ arctigenin (Arc) for 4 or $6 \mathrm{~h}$, and harvested. Total RNA was extracted from the cells and subjected to RT-PCR to detect the mRNA expression of EDEM2, EDEM1, GADD34, GRP94, CHOP, GRP78/BiP, ATF6 $\alpha$ and GAPDH. (B and C) Effects of arctigenin and p38 MAPK inhibitor on the promoter activities of GRP78/BiP and ATF6 $\alpha$ genes. HeLa cells transfected with the luciferase reporter plasmids containing the GRP78 or ATF6a promoter were cultured in glucose-free medium with $10 \mu \mathrm{M}$ arctigenin, $100 \mu \mathrm{M}$ SB203580 or $100 \mu \mathrm{M} \mathrm{SB} 202190$ for $4 \mathrm{~h}$, and lysed in buffer for luciferase analysis. The promoter activities of GRP78 and ATF6 $\alpha$ in drug-untreated and glucose-deprived cells is defined as $100 \%$ relative activity. ${ }^{*} \mathrm{P}<0.01$ and ${ }^{* *} \mathrm{P}<0.001$ indicate a statistically significantly difference compared with the untreated cell; ns, not significant. (D) The level of ATF6 $\alpha$ protein in arctigenin-treated cells. BCBL1 and DG75 cells were incubated with glucose-free medium with 5 or $10 \mu \mathrm{M}$ arctigenin for $6 \mathrm{~h}$, and cell lysates were probed by blotting using an antibody that recognizes ATF6 $\alpha$ N-terminal region and ATF6 $\alpha$ cleaved form, p50 ATF6 $\alpha$ (left panels). HeLa cells were transfected with N-terminal FLAG-tagged ATF6 $\alpha$ by the Chen and Okayama calcium-phosphate method (37) and were treated with $5 \mu \mathrm{M}$ arctigenin for $6 \mathrm{~h}$. Cell lysates were subjected to blotting using Flag antibody (right panel).

with glucose was decreased by 60 and $25 \%$ following treatment with 100 and $50 \mu \mathrm{M}$ of $\mathrm{U} 1026$, respectively $(13,14)$.

Arctigenin and p38 MAPK inhibitor suppress the transcriptional expression of GRP78/BipandATF6 ainglucose-deprived PEL cells. Arctigenin inhibited ERK and p38 MAPK signaling in glucose-deprived PEL cells (Fig. 4). Cytokines and forms of cellular stress, such as UV irradiation, heat shock and osmotic changes, have been known to activate p38 MAPK signaling, which correlates with the upregulation of the UPR including GRP78/BiP, CHOP and ATF6 $\alpha(43,44)$. Furthermore, it has been reported that arctigenin blocks the UPR and the expression of GRP78, CHOP, ATF4 and XBP1 $(28,29)$. Therefore, in this study, we investigated whether arctigenin downregulates the mRNA expression of ER stress-related molecules in PEL cells under conditions of glucose deprivation. GRP78 and GRP94 are ER stress-inducible ER chaperones. GRP78, also known as BiP, plays an essential role in the UPR (45). ER degradation enhancing $\alpha$-mannosidase-like proteins (EDEMs) are ER membrane proteins and are involved in ER-associated degradation (ERAD). EDEM1/2 targets misfolded glycoproteins for degradation in an N-glycan-dependent manner (45). ATF6 $\alpha$ is a UPR-related transcription factor and activates the transcriptional expression of GRP78. CHOP is also an UPR-related transcription factor and transcriptionally upregulates GADD34 which induces a translation block (46). In this study, the mRNA expression levels of these molecules in cells cultured in glucose-free medium with (or without) arctigenin were measured by RT-PCR (Fig. 6A). Arctigenin increased the mRNA levels of GRP94 and CHOP in the glucose-deprived PEL and uninfected cells. The expression of GADD34 was slightly upregulated in the arctigenin-treated $\mathrm{BC} 3$ and uninfected cells. In addition, GRP78 and ATF6 $\alpha$ exhibited very low levels of transcription in all cell types in the absence of glucose; however, arctigenin decreased the transcription of GRP78 and ATF6 $\alpha$. By contrast, EDEM1 and EDEM2 exhibited high levels of transcription in all cell types, while arctigenin did not affect the transcription of these molecules.

As the mRNA expression levels of GRP78 and ATF6 $\alpha$ were decreased in the arctigenin-treated cells, we examined whether arctigenin inhibits the transcription of these genes by a luciferase reporter assay using the promoter sequences of GRP78 or ATF6 $\alpha$. HeLa cells transfected with GRP78 or ATF6 $\alpha$ promoter-driven luciferase reporter plasmids were incubated in glucose-free medium with arctigenin or p38 MAPK inhibitors (SB203580 and SB202190) for $4 \mathrm{~h}$, and cell extracts were 


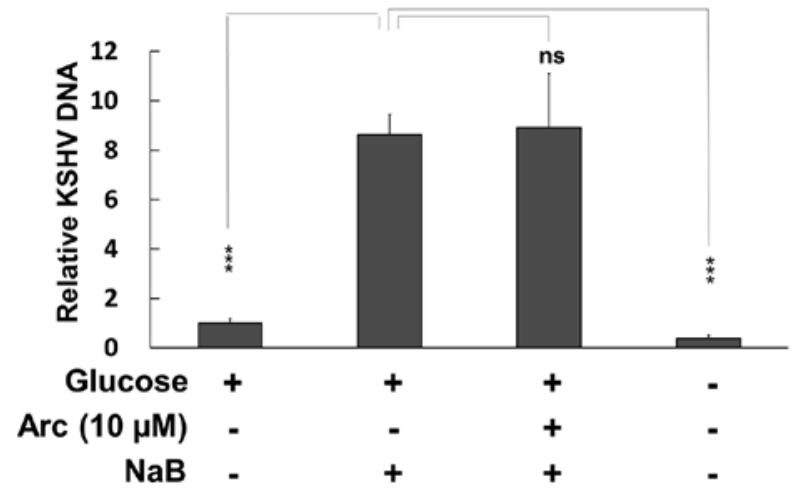

Figure 7. Effects of arctigenin on KSHV lytic replication in BC3 cells. BC3 cells were cultured for $48 \mathrm{~h}$ with (or without) $10 \mu \mathrm{M}$ arctigenin in RPMI medium containing $3 \mathrm{mM}$ sodium butyrate $(\mathrm{NaB})$. $\mathrm{NaB}$ was used to induce KSHV lytic replication. Culture medium containing viral particles was harvested and KSHV genome copy numbers were quantified by real-time PCR. The KSHV genome copy number in non-induced and arctigenin-untreated BC3 cells was defined as 1.0 . $^{* * *} \mathrm{P}<0.001$ indicates a statistically significantly difference compared with the NaB-treated and arctigenin-untreated BC 3 cells.

subjected to measure luciferase activities. The results revealed that arctigenin markedly suppressed GRP78 and ATF6 $\alpha$ promoter activities in the HeLa cells cultured in glucose-free medium (Fig. 6B and C). In addition to arctigenin, GRP78 promoter activity was decreased by $\sim 40 \%$ by glucose depletion and either SB203580 or SB202190 treatment (Fig. 6B), while ATF6 $\alpha$ promoter activity was decreased by $\sim 70$ and $50 \%$ by SB203580 or SB202190 treatment, respectively (Fig. 6C). These data indicate that arctigenin and p38 MAPK inhibition downregulate the mRNA expression of GRP78 and ATF6 $\alpha$ under conditions of glucose deprivation. We then wished to elucidate whether arctigenin treatment alters the protein expression of ATF6 $\alpha$. The BCBL1 and DG75 cells were incubated in glucosefree medium with arctigenin, and the amount of ATF6 $\alpha$ protein was detected by western blot analysis using an antibody that recognizes the N-terminal region of both full-length ATF6 $\alpha$ and p50 ATF6 $\alpha$, which is the cleaved form of ATF6 $\alpha$ containing the transcriptional activation domain (Fig. 6D, left panel). HeLa cells transfected with N-terminal Flag-tagged ATF6 $\alpha$ were treated with arctigenin, and were then examined by western blot analysis using a Flag antibody (Fig. 6D, right panel). As a result, the amount of ATF6 $\alpha$ protein was decreased in the arctigenin-treated BCBL1 and DG75 cells, and the amount of p50 ATF6 $\alpha$ was also decreased in the arctigenin-treated DG75 and HeLa cells. These data suggest that arctigenin suppressed not only the expression of ATF6 $\alpha$, but also the production of p50 ATF6 $\alpha$.

Effects of arctigenin on KSHV replication in PEL. Previous studies have indicated that cellular stress, such as ER stress, oxidative stress and hypoxia, reactivates latent KSHV infection and induces lytic replication in PEL cells $(47,48)$. Therefore, in this study, we evaluated whether arctigenin enhances (or suppresses) de novo KSHV production in BC3 PEL cells cultured in normal medium. BC3 cells were treated with $3 \mathrm{mM} \mathrm{NaB}$ in the presence or absence of arctigenin for $48 \mathrm{~h}$, and the culture media were harvested. Viral DNA purified from culture media was quantified by real-time PCR (Fig. 7). $\mathrm{NaB}$ treatment was used for the induction of lytic replication.
As a result, $\mathrm{NaB}$ prominently increased viral production by the BC 3 cells cultured in culture medium containing glucose; however, arctigenin neither enhanced nor suppressed viral production at $10 \mu \mathrm{M}$, which also did not affect BC3 cell growth (Fig. 1A). These results indicate that arctigenin may kill PEL cells without the risk of de novo KSHV infection and production.

\section{Discussion}

PEL is a rare subtype of large B-cell lymphoma associated with $\mathrm{KSHV}$ and it has the highest incidence rate in HIV-positive individuals. In the majority of cases, PEL is present as a malignant pleural, peritoneal or pericardial effusion without a detectable solid mass. However, in rare cases, solid variants of PEL are present as solid tumor masses or extracavitary solid tumors (49,50). In general, chemotherapeutic drugs targeting the proliferation machinery of tumor cells also damage proliferating normal cells, such as hematopoietic stem cells. Hence, the development of tumor-specific anticancer agents is required for safe and effective cancer therapy. The tumor tissue environment is known to lack oxygen and glucose compared with normal tissues. Thus, selectively targeting metabolically stressed (glucose-deprived) tumor cells, including PEL, may represent a promising strategy with which to inhibit tumor cell proliferation without affecting normal cells. In this regard, arctigenin has been shown to preferentially induce tumor growth suppression and apoptosis in glucose-deprived tumor cells (34-36). In this study, we examined a novel biological function of arctigenin and the molecular mechanisms through which it preferentially induces the apoptosis of glucosestarved PEL cells. We propose a model in which arctigenin downregulates MAPK signaling and induces mitochondrial disruption, leading to PEL cell death (Fig. 8).

Based on our understanding of KSHV-infected PEL and the biochemical properties of arctigenin, we hypothesize 3 possible mechanisms through which arctigenin induces the apoptosis of PEL cells under conditions of glucose deprivation: i) mitochondrial disruption; ii) suppression of the ERK and p38 MAPK pathways which are involved in the proliferation and survival of PEL cells; and iii) the suppression of ATF6 $\alpha$ and GRP78 expression. We can surmise that the cytotoxic effects of arctigenin in glucose-deprived PEL cells may be mediated via a combination of these mechanisms.

Arctigenin has been shown to induce a decrease in ATP production $(36,30,51)$ and mitochondrial membrane disruption $(21,25,30)$ in glucose-deprived tumor cells. Previous studies have suggested that arctigenin inhibits complex I, II and IV of the mitochondrial respiratory chain $(21,36,30)$ and consequently causes mitochondrial membrane disruption, which results in an increase in cytochrome c release and cytochrome c-related reactive oxygen species (ROS) production, thereby decreasing intracellular ATP levels. These studies are in agreement with the findings of the present study on arctigenin-treated PEL cells. We found that arctigenin led to a loss of mitochondrial membrane potential (Fig. 3B), decreased intracellular ATP levels (Fig. 3C and D) and increased caspase-9 activation (Fig. 3A) in glucose-deprived PEL cells, suggesting that the arctigenin-induced apoptosis was mitochondrial dependent. 

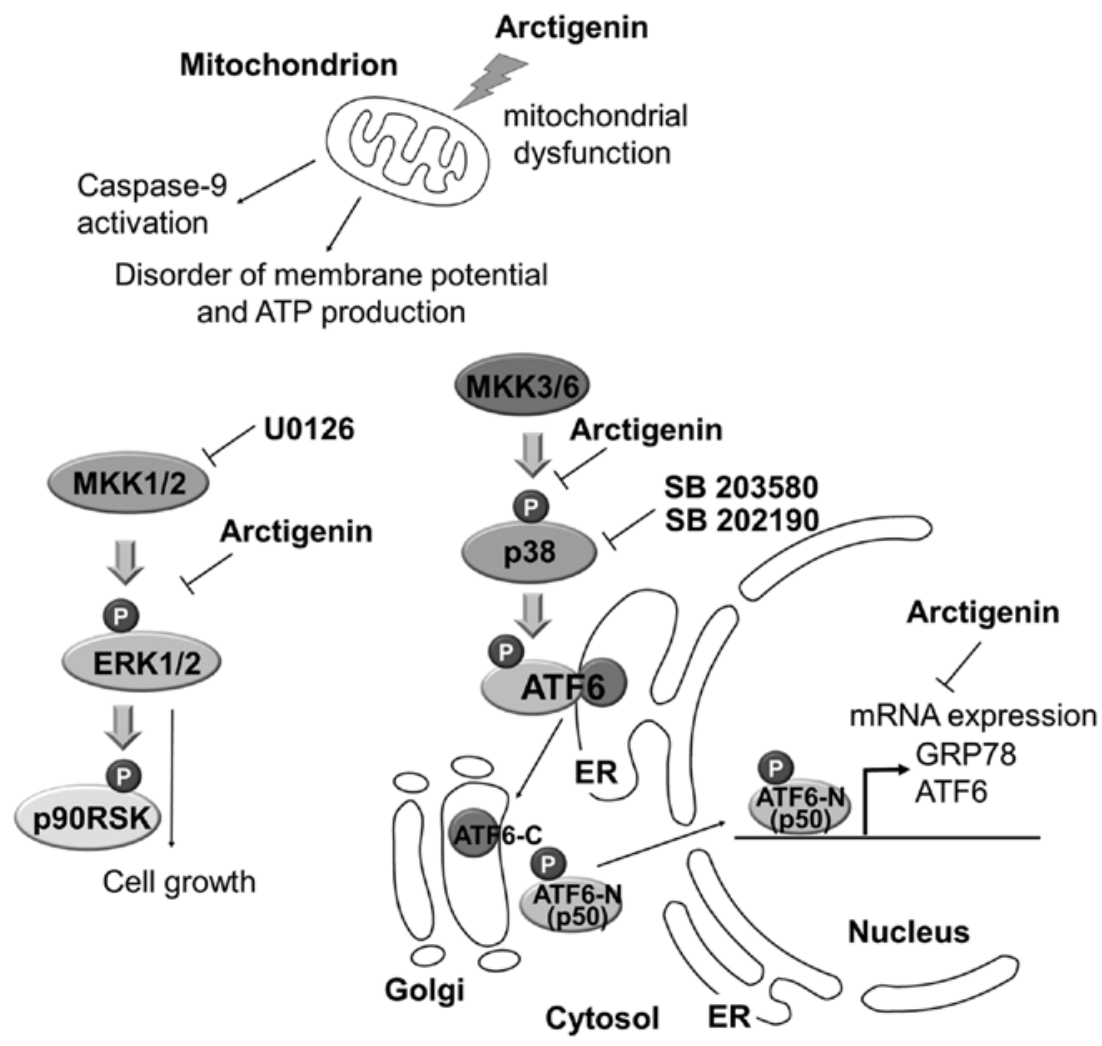

Figure 8. Model of arctigenin-mediated inhibition of PEL cell growth. Arctigenin induced a decrease in ATP levels, the disruption of mitochondrial membrane potential and apoptosis via caspase-9 activation in PEL cells under conditions of glucose deprivation. Arctigenin-induced mitochondrial disruption correlates with caspase-9-mediated apoptosis. The ERK and p38 MAPK signaling pathways are known to be required for KSHV to establish infection, maintain malignant phenotypes and cell survival in a host cell. In addition to mitochondrial disruption, arctigenin suppresses the ERK and p38 MAPK pathways in glucose-deprived PEL cells, resulting in the inhibition of cell proliferation. On the other hand, various cellular stresses activate p38 MAPK, which enhances the UPR, including the ATF6 $\alpha$ along with the p38 MAPK-mediated phosphorylation and cleavage of ATF6 $\alpha$. Cleaved ATF6 $\alpha$ (p50ATF6/ATF6-N) induces transcriptional activation of GRP78 and ATF6 $\alpha$ itself. Arctigenin inhibits not only the p38 MAPK pathway, but also the expression of GRP78, ATF6 $\alpha$ and p50 ATF6 $\alpha$. Hence, the suppression may be due to an increase in ER stress, which can cause the apoptosis of PEL cells.

In addition to mitochondrial damage, arctigenin has been known to cause cell cycle arrest or apoptosis by modulating various signaling pathways, including STAT3 (22), Akt $(23,24,34)$, NF- $\mathrm{kB}(24)$, p38 MAPK $(25,26)$ and ERK $(24,27)$. MAPKs, including ERK, p38 MAPK and JNK, are involved in the development, proliferation and progression of cancer. In addition, p38 MAPK and JNK are also associated with various stress responses. ERK is mainly activated by growth factors, while p38 and JNK are activated by cytokines, growth factors and cellular stresses, such as ER stress, UV irradiation and heat shock (52). It has been reported that arctigenin activates p38 MAPK signaling, as well as ROS production $(25,26)$ and inhibits ERK signaling $(24,27)$. By contrast, other studies have found that arctigenin suppresses p38 MAPK signaling in lipopolysaccharide (LPS)-treated RAW264.7 cells $(53,54)$. In this study, our data are in line with these findings, in that ERK and p38 MAPK activation were suppressed by arctigenin in PEL cells under glucose-deprived conditions (Fig. 4). We hypothesize that these conflicting results of different studies as mentioned above may be due to differences in the genetic background of the tested cancer cells, KSHV infection, glucose conditions during viability assays, or the assayed arctigenin concentrations.

As described above, arctigenin treatment strongly perturbs cellular signaling cascades that are essential for KSHV to maintain a malignant phenotype and ensure survival in an infected cell, including PEL and Kaposi's sarcoma. The constitutive and/or transient activation of several signaling pathways, such as NF- $\mathrm{KB}$, Akt, Wnt and ERK, is known to be necessary for KSHV to establish and maintain infection, cell proliferation, viral lytic replication and cell survival in a host cell (7-10). In fact, we have previously demonstrated that the suppression of NF- $\mathrm{BB}$, Akt and ERK signaling by diallyl trisulfide (12), pyrrolidinium fullerene derivatives (13) and sangivamycin (14), respectively, inhibits the growth and the apoptosis of PEL cells. In particular, the activation of p38 MAPK is required for primary infection $(39,42)$, persistent infection $(40,55)$, tumorigenicity and angiogenic potential (56), reactivation (i.e., lytic replication) $(42,57)$ and ROS stress response $(47,58)$. In addition, ERK signaling plays an important role in the establishment of infection $(41,42,59)$, the expression of viral genes $(41,42)$, survival (14), lytic replication (42) and the activation of cellular transcription factors, such as c-Fos, c-Jun, STAT1 $\alpha$ and c-Myc (41). These observations are consistent with our data. Namely, arctigenin reduced the proliferation of PEL cells and suppressed the phosphorylation of p38 MAPK, ERK and p90RSK under conditions of glucose deprivation (Fig. 4). Furthermore, the suppression of p38 MAPK and ERK by a specific inhibitor decreased the proliferation of the PEL cells (Fig. 5). Therefore, it can by hypothesized that p38 MAPK inhibition or/and ERK inhibition by arctigenin may disrupt the function of these signaling 
pathways (i.e., persistent infection, tumorigenicity, stress response and gene expression), thus resulting in growth inhibition and the apoptosis of PEL cells. It can also be hypothesized that the arctigenin-induced inhibitory effects on these kinases may lead to antitumor activities against KSHV-infected PEL, but not KSHV-uninfected B-lymphoma.

ER stress, such as ROS, misfolded proteins and denatured protein generation, leads to the UPR, which induces the expression of ER chaperones and ER-related molecules to facilitate the refolding or the degradation of misfolded proteins and to suppress the translation of de novo proteins. UPR is primarily regulated by GRP78, and consists of 3 pathways involving ATF6 $\alpha$, IRE1 $\alpha$ and PERK (45). Under normal conditions, GRP78 interacts with and inactivates ATF6 $\alpha$, IRE1 $\alpha$ and PERK, but dissociates from these during ER stress, which activates these pathways. In an ER stress-dependent manner, ER-localized ATF6 $\alpha$ is translocated into the Golgi apparatus and is cleaved. Cleaved ATF6 $\alpha$ (p50 ATF6 $\alpha$ ) is then translocated to the nucleus, which in turn activates the transcriptional expression of ER chaperones, such as GRP78, GRP94, XBP1, EDEM1/2 and ATF6 $\alpha$ itself $(45,46)$. IRE1 induces the splicing of immature XBP1 mRNA, and the translated XBP1 protein activates the transcription of GRP78 and XBP1 itself. PERK phosphorylates eIF2 $\alpha$, and induces a translation block. However, in the presence of severe ER stress, pro-apoptotic UPR is activated. Pro-apoptotic UPR activates the expression of the transcription factor, CHOP, which transcriptionally upregulates GADD34 and pro-apoptotic Bcl-2 proteins, leading to apoptosis $(45,46)$. As for the association between arctigenin and UPR, arctigenin has been shown to induce ROS production $(25,26,36)$ and ER stress along with the UPR (30). By contrast, arctigenin has been reported to inhibit UPR and alleviate brefeldin A-induced ER stress by activating AMP-activated protein kinase (51). Furthermore, arctigenin has been known to inhibit the UPR by the transcriptional suppression of GRP78, GRP94 or CHOP, resulting in a reduction of ER stress, pro-apoptotic UPR or apoptosis $(28,29,51)$. These observations are partially in agreement with the findings of the present study on glucose-deprived PEL cells, as we observed an upregulation in GRP94, GADD34 and CHOP expression, and a downregulation in GRP78 and ATF6 $\alpha$ expression. These discrepancies may be due to differences in KSHV infection or genetic backgrounds of the tested cells. Indeed, we have previously found that the mRNA expression levels of IRE1 $\alpha$ and PERK are decreased in PEL cells compared with KSHV-uninfected cells under normal culture conditions, and KSHV-encoded LANA and v-cyclin D suppressed IRE1 $\alpha$ transcription (15). In this study, we found that arctigenin suppressed the phosphorylation (i.e., the activation) of p38 MAPK and the expression of GRP78, ATF6 $\alpha$ and p50 ATF6 $\alpha$ in glucose-deprived PEL cells (Figs. 4 and 6). In addition, a p38 MAPK inhibitor also suppressed cell growth (Fig. 5B and C) and the promoter activities of the GRP78 and ATF6 $\alpha$ genes (Fig. 6B and C) in glucose-deprived cells. These findings are consistent with previous studies, which indicate that the activation of p38 MAPK upregulates GRP78 expression $(60,61)$, induces the phosphorylation and cleavage of ATF6 $\alpha$, and then activates p50 ATF6 $\alpha$ in an ATF6 $\alpha$-phosphorylation-dependent manner $(43,44)$. It can thus be hypothesized that arctigenin suppresses the p38 MAPK-mediated ATF6 $\alpha$ activation (or cleavage), which in turn suppresses the ATF6 $\alpha$-mediated transcription of GRP78 and ATF6 $\alpha$ itself. These disruptions of UPR can evoke severe ER stress and subsequent apoptosis through pro-apoptotic UPR activation, including $\mathrm{CHOP}$ and GADD34 expression in PEL cells (Fig. 6A).

In conclusion, the findings of this study demonstrate that arctigenin treatment induces mitochondrial disruption, the suppression of the ERK and p38 MAPK pathways, and the downregulation of ATF6 $\alpha$ and GRP78 expression in glucosedeprived PEL cells. These phenotypes of arctigenin can serve as cytotoxic effectors in glucose-deprived PEL cells. Therefore, PEL cells are more sensitive to the anti-proliferative effects of arctigenin than $\mathrm{KSHV}$-uninfected cells, thereby raising the possibility that arctigenin may serve as a novel therapeutic agent in the treatment of KSHV-associated lymphoma.

\section{Acknowledgements}

This study was supported in part by a Grant-in-Aid for Scientific Research (C) (15K07952), Young Scientists (B) (16K18925) and Strategic Research Foundation at Private Universities (S1311035) from MEXT of Japan, and by the Japan Agency for Medical Research and Development (16fk0410107h0201). We would like to thank Dr Peter Gee (Kyoto University, Kyoto, Japan) for critically proofreading the manuscript.

\section{References}

1. Russo JJ, Bohenzky RA, Chien MC, Chen J, Yan M, Maddalena D, Parry JP, Peruzzi D, Edelman IS, Chang Y, et al: Nucleotide sequence of the Kaposi sarcoma-associated herpesvirus (HHV8). Proc Natl Acad Sci USA 93: 14862-14867, 1996.

2. Nador RG, Cesarman E, Chadburn A, Dawson DB, Ansari MQ, Sald J and Knowles DM: Primary effusion lymphoma: A distinct clinicopathologic entity associated with the Kaposi's sarcomaassociated herpes virus. Blood 88: 645-656, 1996.

3. Antar A, El Hajj H, Jabbour M, Khalifeh I, El-Merhi F, Mahfouz R and Bazarbachi A: Primary effusion lymphoma in an elderly patient effectively treated by lenalidomide: Case report and review of literature. Blood Cancer J 4: e190, 2014.

4. Boulanger E, Gérard L, Gabarre J, Molina JM, Rapp C, Abino JF, Cadranel J, Chevret S and Oksenhendler E: Prognostic factors and outcome of human herpesvirus 8-associated primary effusion lymphoma in patients with AIDS. J Clin Oncol 23: 4372-4380, 2005.

5. Carbone A and Gloghini A: KSHV/HHV8-associated lymphomas. Br J Haematol 140: 13-24, 2008.

6. Okada S, Goto H and Yotsumoto M: Current status of treatment for primary effusion lymphoma. Intractable Rare Dis Res 3: 65-74, 2014

7. Damania B and Cesarman E: Kaposi's sarcoma-associated herpesvirus. In: Fields Virology. Knipe DM and Howley PM (eds). Vol 2. 6th edition. Lippincott Williams \& Wilkins, Philadelphia, pp2080-2128, 2013.

8. Schulz TF and Cesarman E: Kaposi Sarcoma-associated Herpesvirus: Mechanisms of oncogenesis. Curr Opin Virol 14: 116-128, 2015.

9. Fujimuro M, Wu FY, ApRhys C, Kajumbula H, Young DB, Hayward GS and Hayward SD: A novel viral mechanism for dysregulation of beta-catenin in Kaposi's sarcoma-associated herpesvirus latency. Nat Med 9: 300-306, 2003.

10. Ashizawa A, Higashi C, Masuda K, Ohga R, Taira $T$ and Fujimuro M: The Ubiquitin system and Kaposi's sarcomaassociated herpesvirus. Front Microbiol 3: 66, 2012.

11. Sun R, Lin SF, Gradoville L, Yuan Y, Zhu F and Miller G: A viral gene that activates lytic cycle expression of Kaposi's sarcoma-associated herpesvirus. Proc Natl Acad Sci USA 95: 10866-10871, 1998.

12. Shigemi Z, Furukawa Y, Hosokawa K, Minami S, Matsuhiro J, Nakata S, Watanabe T, Kagawa H, Nakagawa K, Takeda H, et al: Diallyl trisulfide induces apoptosis by suppressing NF- $\kappa \mathrm{B}$ signaling through destabilization of TRAF6 in primary effusion lymphoma. Int J Oncol 48: 293-304, 2016. 
13. Watanabe T, Nakamura S, Ono T, Ui S, Yagi S, Kagawa H, Watanabe H, Ohe T, Mashino T and Fujimuro M: Pyrrolidinium fullerene induces apoptosis by activation of procaspase-9 via suppression of Akt in primary effusion lymphoma. Biochem Biophys Res Commun 451: 93-100, 2014.

14. Wakao K, Watanabe T, Takadama T, Ui S, Shigemi Z, Kagawa H, Higashi C, Ohga R, Taira T and Fujimuro M: Sangivamycin induces apoptosis by suppressing Erk signaling in primary effusion lymphoma cells. Biochem Biophys Res Commun 444: $135-140,2014$.

15. Shigemi Z, Baba Y, Hara N, Matsuhiro J, Kagawa H, Watanabe T and Fujimuro M: Effects of ER stress on unfolded protein responses, cell survival, and viral replication in primary effusion lymphoma. Biochem Biophys Res Commun 469: 565-572, 2016.

16. Shigemi Z, Manabe K, Hara N, Baba Y, Hosokawa K, Kagawa H, Watanabe T and Fujimuro M: Methylseleninic acid and sodium selenite induce severe ER stress and subsequent apoptosis through UPR activation in PEL cells. Chem Biol Interact 266: 28-37, 2017.

17. Bastos JK, Carvalho JC, de Souza GH, Pedrazzi AH and Sarti SJ: Anti-inflammatory activity of cubebin, a lignan from the leaves of Zanthoxyllum naranjillo Griseb. J Ethnopharmacol 75 279-282, 2001

18. Swarup V, Ghosh J, Mishra MK and Basu A: Novel strategy for treatment of Japanese encephalitis using arctigenin, a plant lignan. J Antimicrob Chemother 61: 679-688, 2008.

19. Hayashi K, Narutaki K, Nagaoka Y, Hayashi T and Uesato S: Therapeutic effect of arctiin and arctigenin in immunocompetent and immunocompromised mice infected with influenza A virus Biol Pharm Bull 33: 1199-1205, 2010.

20. Jang YP, Kim SR, Choi YH, Kim J, Kim SG, Markelonis GJ $\mathrm{Oh} \mathrm{TH}$ and Kim YC: Arctigenin protects cultured cortica neurons from glutamate-induced neurodegeneration by binding to kainate receptor. J Neurosci Res 68: 233-240, 2002.

21. Huang SL, Yu RT, Gong J, Feng Y, Dai YL, Hu F, Hu YH, Tao YD and Leng Y: Arctigenin, a natural compound, activates AMP-activated protein kinase via inhibition of mitochondria complex I and ameliorates metabolic disorders in ob/ob mice. Diabetologia 55: 1469-1481, 2012.

22. Yao X, Zhu F, Zhao Z, Liu C, Luo L and Yin Z: Arctigenin enhances chemosensitivity of cancer cells to cisplatin through inhibition of the STAT3 signaling pathway. J Cell Biochem 112: 2837-2849, 2011

23. Jiang X, Zeng L, Huang J, Zhou H and Liu Y: Arctigenin, a natural lignan compound, induces apoptotic death of hepatocellular carcinoma cells via suppression of PI3-K/Akt signaling. J Biochem Mol Toxicol 29: 458-464, 2015.

24. Maxwell T, Chun SY, Lee KS, Kim S and Nam KS: The anti-metastatic effects of the phytoestrogen arctigenin on human breast cancer cell lines regardless of the status of ER expression. Int J Oncol 50: 727-735, 2017.

25. Li QC, Liang Y, Tian Y and Hu GR: Arctigenin induces apoptosis in colon cancer cells through ROS/p38MAPK pathway. J BUON 21: 87-94, 2016.

26. Hsieh CJ, Kuo PL, Hsu YC, Huang YF, Tsai EM and Hsu YL: Arctigenin, a dietary phytoestrogen, induces apoptosis of estrogen receptor-negative breast cancer cells through the ROS/p38 MAPK pathway and epigenetic regulation. Free Radic Biol Med 67: 159-170, 2014.

27. Zhang M, Cai S, Zuo B, Gong W, Tang Z, Zhou D, Weng M, Qin Y, Wang S, Liu J, et al: Arctigenin induced gallbladder cancer senescence through modulating epidermal growth factor receptor pathway. Tumour Biol 39: 1010428317698359, 2017.

28. Kim JY, Hwang JH, Cha MR, Yoon MY, Son ES, Tomida A, Ko B, Song SW, Shin-ya K, Hwang YI, et al: Arctigenin blocks the unfolded protein response and shows therapeutic antitumor activity. J Cell Physiol 224: 33-40, 2010.

29. Sun S, Wang X, Wang C, Nawaz A, Wei W, Li J, Wang L and Yu DH: Arctigenin suppresses unfolded protein response and sensitizes glucose deprivation-mediated cytotoxicity of cancer cells. Planta Med 77: 141-145, 2011.

30. Brecht K, Riebel V, Couttet P, Paech F, Wolf A, Chibout SD, Pognan F, Krähenbühl S and Uteng M: Mechanistic insights into selective killing of OXPHOS-dependent cancer cells by arctigenin. Toxicol In Vitro 40: 55-65, 2017.

31. Jeong JB, Hong SC, Jeong HJ and Koo JS: Arctigenin induces cell cycle arrest by blocking the phosphorylation of $\mathrm{Rb}$ via the modulation of cell cycle regulatory proteins in human gastric cancer cells. Int Immunopharmacol 11: 1573-1577, 2011.

32. Kudou N, Taniguchi A, Sugimoto K, Matsuya Y, Kawasaki M, Toyooka N, Miyoshi C, Awale S, Dibwe DF, Esumi H, et al: Synthesis and antitumor evaluation of arctigenin derivatives based on antiausterity strategy. Eur J Med Chem 60: 76-88, 2013
33. Huang K, Li LA, Meng YG, You YQ, Fu XY and Song L: Arctigenin promotes apoptosis in ovarian cancer cells via the iNOS/NO/STAT3/survivin signalling. Basic Clin Pharmacol Toxicol 115: 507-511, 2014

34. Awale S, Lu J, Kalauni SK, Kurashima Y, Tezuka Y, Kadota S and Esumi H: Identification of arctigenin as an antitumor agent having the ability to eliminate the tolerance of cancer cells to nutrient starvation. Cancer Res 66: 1751-1757, 2006.

35. Ikeda M, Sato A, Mochizuki N, Toyosaki K, Miyoshi C, Fujioka R, Mitsunaga S, Ohno I, Hashimoto Y, Takahashi H, et al: Phase I trial of GBS-01 for advanced pancreatic cancer refractory to gemcitabine. Cancer Sci 107: 1818-1824, 2016.

36. Gu Y, Qi C, Sun X, Ma X, Zhang H, Hu L, Yuan J and Yu Q: Arctigenin preferentially induces tumor cell death under glucose deprivation by inhibiting cellular energy metabolism. Biochem Pharmacol 84: 468-476, 2012.

37. Chen $\mathrm{C}$ and Okayama $\mathrm{H}$ : High-efficiency transformation of mammalian cells by plasmid DNA. Mol Cell Biol 7: 2745-2752, 1987.

38. Takayanagi S, Fukuda R, Takeuchi Y, Tsukada S and Yoshida K: Gene regulatory network of unfolded protein response genes in endoplasmic reticulum stress. Cell Stress Chaperones 18: 11-23, 2013.

39. Xie J, Pan H, Yoo S and Gao SJ: Kaposi's sarcoma-associated herpesvirus induction of AP-1 and interleukin 6 during primary infection mediated by multiple mitogen-activated protein kinase pathways. J Virol 79: 15027-15037, 2005.

40. Sharma-Walia N, Patel K, Chandran K, Marginean A, Bottero V, Kerur N and Paul AG: COX-2/PGE2: Molecular ambassadors of Kaposi's sarcoma-associated herpes virus oncoprotein-v-FLIP. Oncogenesis 1: e5, 2012.

41. Sharma-Walia N, Krishnan HH, Naranatt PP, Zeng L, Smith MS and Chandran B: ERK1/2 and MEK1/2 induced by Kaposi's sarcoma-associated herpesvirus (human herpesvirus 8 ) early during infection of target cells are essential for expression of viral genes and for establishment of infection. J Virol 79: 10308-10329, 2005.

42. Pan H, Xie J, Ye F and Gao SJ: Modulation of Kaposi's sarcoma-associated herpesvirus infection and replication by MEK/ERK, JNK, and p38 multiple mitogen-activated protein kinase pathways during primary infection. J Virol 80: 5371-5382, 2006.

43. Gade P, Manjegowda SB, Nallar SC, Maachani UB, Cross AS and Kalvakolanu DV: Regulation of the death-associated protein kinase 1 expression and autophagy via ATF6 requires apoptosis signal-regulating kinase 1. Mol Cell Biol 34: 4033-4048, 2014.

44. Egawa N, Yamamoto K, Inoue H, Hikawa R, Nishi K, Mori K and Takahashi R: The endoplasmic reticulum stress sensor, ATF6 $\alpha$, protects against neurotoxin-induced dopaminergic neuronal death. J Biol Chem 286: 7947-7957, 2011.

45. Wang M and Kaufman RJ: Protein misfolding in the endoplasmic reticulum as a conduit to human disease. Nature 529: 326-335, 2016.

46. Sovolyova N, Healy S, Samali A and Logue SE: Stressed to death - mechanisms of ER stress-induced cell death. Biol Chem 395: $1-13,2014$.

47. Li X, Feng J and Sun R: Oxidative stress induces reactivation of Kaposi's sarcoma-associated herpesvirus and death of primary effusion lymphoma cells. J Virol 85: 715-724, 2011.

48. Leung HJ, Duran EM, Kurtoglu M, Andreansky S, Lampidis TJ and Mesri EA: Activation of the unfolded protein response by 2 -deoxy-D-glucose inhibits Kaposi's sarcoma-associated herpesvirus replication and gene expression. Antimicrob Agents Chemother 56: 5794-5803, 2012.

49. Liao G, Cai J, Yue C and Qing X: Extracavitary/solid variant of primary effusion lymphoma presenting as a gastric mass. Exp Mol Pathol 99: 445-448, 2015.

50. Katz H, Rose C, Rivera NT and Bray N: HIV-associated primary effusion lymphoma presenting as a paracardial mass. BMJ Case Rep 2015: bcr2014208718, 2015.

51. Gu Y, Sun XX, Ye JM, He L, Yan SS, Zhang HH, Hu LH, Yuan JY and Yu Q: Arctigenin alleviates ER stress via activating AMPK. Acta Pharmacol Sin 33: 941-952, 2012.

52. Ichijo H: From receptors to stress-activated MAP kinases. Oncogene 18: 6087-6093, 1999.

53. Cho MK, Jang YP, Kim YC and Kim SG: Arctigenin, a phenylpropanoid dibenzylbutyrolactone lignan, inhibits MAP kinases and AP-1 activation via potent MKK inhibition: The role in TNF-alpha inhibition. Int Immunopharmacol 4: 1419-1429, 2004. 
54. Lee JY, Cho BJ, Park TW, Park BE, Kim SJ, Sim SS and Kim CJ: Dibenzylbutyrolactone lignans from Forsythia koreana fruits attenuate lipopolysaccharide-induced inducible nitric oxide synthetase and cyclooxygenase- 2 expressions through activation of nuclear factor- $\kappa \mathrm{B}$ and mitogen-activated protein kinase in RAW264.7 cells. Biol Pharm Bull 33: 1847-1853, 2010.

55. Li X, Chen S, Feng J, Deng H and Sun R: Myc is required for the maintenance of Kaposi's sarcoma-associated herpesvirus latency. J Virol 84: 8945-8948, 2010.

56. Bais C, Santomasso B, Coso O, Arvanitakis L, Raaka EG Gutkind JS, Asch AS, Cesarman E, Gershengorn MC and Mesri EA: G-protein-coupled receptor of Kaposi's sarcomaassociated herpesvirus is a viral oncogene and angiogenesis activator. Nature 391: 86-89, 1998

57. Sadagopan S, Sharma-Walia N, Veettil MV, Raghu H, Sivakumar R, Bottero V and Chandran B: Kaposi's sarcomaassociated herpesvirus induces sustained NF-kappaB activation during de novo infection of primary human dermal microvascular endothelial cells that is essential for viral gene expression. J Virol 81: 3949-3968, 2007.
58. Ye F, Zhou F, Bedolla RG, Jones T, Lei X, Kang T, Guadalupe M and Gao SJ: Reactive oxygen species hydrogen peroxide mediates Kaposi's sarcoma-associated herpesvirus reactivation from latency. PLoS Pathog 7: e1002054, 2011.

59. Naranatt PP, Akula SM, Zien CA, Krishnan HH and Chandran B: Kaposi's sarcoma-associated herpesvirus induces the phosphatidylinositol 3-kinase-PKC-zeta-MEK-ERK signaling pathway in target cells early during infection: Implications for infectivity. J Virol 77: 1524-1539, 2003.

60. Ranganathan AC, Zhang L, Adam AP and Aguirre-Ghiso JA: Functional coupling of $\mathrm{p} 38$-induced up-regulation of $\mathrm{BiP}$ and activation of RNA-dependent protein kinase-like endoplasmic reticulum kinase to drug resistance of dormant carcinoma cells. Cancer Res 66: 1702-1711, 2006.

61. He B, Luo B, Chen Q and Zhang L: Cigarette smoke extract induces the expression of GRP78 in A549 cells via the p38/MAPK pathway. Mol Med Rep 8: 1683-1688, 2013. 